\title{
LIPÍDIOS MODIFICADOS OBTIDOS A PARTIR DE GORDURA DO LEITE, ÓLEO DE GIRASSOL E ÉSTERES DE FITOSTERÓIS PARA APLICAÇÃO EM SPREADS
}

\author{
Juliana Neves Rodrigues Ract e Luiz Antonio Gioielli* \\ Departamento de Tecnologia Bioquímico-Farmacêutica, Faculdade de Ciências Farmacêuticas, Universidade de São Paulo, Av. \\ Prof. Lineu Prestes, 580, 05508-900 São Paulo - SP, Brasil
}

Recebido em 21/8/07; aceito em 20/6/08; publicado na web em 24/10/08

\begin{abstract}
MODIFIED LIPIDS OBTAINED FROM MILK FAT, SUNFLOWER OIL, AND PHYTOSTEROL ESTERS FOR APPLICATION IN TABLESPREADS. The objective of this paper was to evaluate the modifications in milkfat properties with the addition of sunflower oil (SO) and phytosterol esters (PE) and chemical interesterification. Fatty acid composition, softening point and consistency were determined. The saturation degree of milkfat decreased with the addition of SO and PE. Consequently, milkfat presented lower softening point and consistency. Chemical interesterification caused an increase in softening point due to the formation of higher amounts of trissaturated triacylglycerols with rearrangement. The incorporation of unsaturated fatty acids from SO and PE by milkfat triacylglycerols after chemical reaction caused linearization of consistency curves.
\end{abstract}

Keywords: modified lipids; milkfat; phytosterols.

\section{INTRODUÇÃO}

O termo spread engloba diversos produtos disponíveis no mercado que são utilizados para consumo juntamente com pães e biscoitos, como manteigas, margarinas, cremes vegetais e outros produtos com a mesma função.

As margarinas brasileiras foram tradicionalmente fabricadas, durante muito tempo, pelo processo de hidrogenação parcial, responsável por produzir diversos isômeros geométricos e de posição, incluindo os isômeros trans, devido às infinitas possibilidades de aplicação das gorduras parcialmente hidrogenadas. ${ }^{1}$ Estudos mais recentes sugerem que os ácidos graxos trans são mais deletérios que os ácidos graxos saturados, e que seu consumo está relacionado com a incidência de doenças cardiovasculares e diabetes tipo $2 .^{2}$

Atualmente, portanto, o processo de interesterificação tem sido utilizado pela indústria de gorduras para alterar propriedades de espalhabilidade, pois pode modificar as propriedades físicas das gorduras sem, no entanto, produzir ácidos graxos trans. ${ }^{3} \mathrm{~A}$ interesterificação envolve a redistribuição dos ácidos graxos entre os triacilgliceróis, podendo ocorrer dentro da mesma molécula ou entre moléculas diferentes. O produto modificado resultante apresenta a mesma composição em ácidos graxos do material inicial, mas a composição em triacilgliceróis e as propriedades físicas, como ponto de fusão, curva de sólidos, espalhabilidade e estrutura cristalina, são alteradas. ${ }^{3}$

A manteiga ainda mantém um grande número de adeptos e seu sabor é muito apreciado pelo consumidor, o que pode ser confirmado pelo grande número de produtos com aroma de manteiga presentes no mercado. ${ }^{4}$ Contudo, devido à presença de grande quantidade de ácidos graxos saturados e colesterol na manteiga e por existirem estudos que demonstram que os riscos de doenças do coração podem ser diminuídos baixando-se o nível de colesterol no sangue, o consumo de manteiga tem diminuído. ., $^{\circ}$

A gordura do leite, principal componente da manteiga, apresenta plasticidade dentro de sua larga faixa de fusão, entre -40 e $40{ }^{\circ} \mathrm{C} .{ }^{7} \mathrm{~A}$ temperatura de refrigeração doméstica, cerca de $10{ }^{\circ} \mathrm{C}$, a manteiga

*e-mail: lagio@usp.br essencialmente se comporta como sólido e tem pouca espalhabilidade, enquanto que à temperatura ambiente, na faixa de $20 \mathrm{a} 25^{\circ} \mathrm{C}$, ocorre separação de óleo e exsudação. Sua espalhabilidade ideal ocorre por volta de $15{ }^{\circ} \mathrm{C}$, quando apresenta conteúdo de gordura sólida em torno de $30 \%{ }^{8,9}$

A mistura de gordura do leite com óleos vegetais pode levar a produtos que equilibram a nutrição com as características organolépticas desejáveis e custos de produção mais baixos ${ }^{8}$. A principal tendência está em incorporar o máximo possível de óleo rico em ácidos graxos mono- ou poliinsaturados a esses produtos por razões nutricionais, porém isso leva a dificuldades técnicas quanto à estabilidade de suas características de espalhabilidade e suas propriedades de textura..$^{10,11}$

Para melhorar a plasticidade da manteiga, Rousseau et al..$^{8,12,13}$ realizaram estudos de reestruturação da gordura do leite através de mistura com óleo de canola e posterior interesterificação química, analisando o comportamento de fusão, modificações dos triacilgliceróis, microestrutura, polimorfismo e reologia das misturas. $\mathrm{O}$ rearranjo provocou diferenças significativas nos triacilgliceróis, que se refletiram em alterações no conteúdo de gordura sólida em alguns intervalos de temperatura.

Recentemente, fitosteróis/fitostanóis têm sido adicionados a margarinas especiais que estão comercialmente disponíveis como alimentos funcionais, com capacidade de reduzir os níveis de colesterol total e lipoproteínas de baixa densidade (LDL). Foi provado que seu consumo como parte de uma dieta saudável implica em diminuição no risco de doenças do coração em $25 \%$. Esta combinação pode evitar a necessidade de medicamentos para indivíduos com níveis moderadamente altos de colesterol. ${ }^{14,15}$

Os ésteres de estanol ou esterol, puros, em dosagens de $2 \mathrm{~g} / \mathrm{dia}$, diminuem o LDL em $10 \%$ ou mais. Quando consumidas juntamente com uma dieta que visa a diminuir o colesterol, margarinas contendo ésteres de sitostanol reduzem o LDL em pelo menos mais 5\%. ${ }^{16}$

Este trabalho teve como objetivo estudar as modificações nas propriedades físicas da gordura do leite causadas pela adição de óleo de girassol e de ésteres de fitosteróis, bem como pelo processo de interesterificação química. 


\section{PARTE EXPERIMENTAL}

\section{Material}

A gordura do leite foi obtida a partir de manteiga tipo extra sem sal (Paulista, Brasil) por fusão completa à temperatura de $60-70{ }^{\circ} \mathrm{C}$, separação da fase gordurosa por decantação e filtração. $\mathrm{O}$ óleo de girassol refinado Liza (Cargill, Brasil) foi utilizado sem tratamento adicional. Os ésteres de fitosteróis (L\&P Food Ingredient Co., Ltd., Guangdong Food Industry Institute, China) foram doados pela empresa Tovani Benzaquen Representações Ltda.

\section{Misturas}

Para o estudo das interações em misturas ternárias de gorduras foi realizado um planejamento de 8 experimentos, apresentado na Tabela 1. A gordura do leite é representada por $\mathrm{x}_{1}, \mathrm{o}$ óleo de girassol é representado por $\mathrm{x}_{2} \mathrm{e}$ os ésteres de fitosteróis são representados por $\mathrm{x}_{3}$, sendo que $\mathrm{x}_{1}+\mathrm{x}_{2}+\mathrm{x}_{3}=1$ ou $100 \%$.

Tabela 1. Planejamento experimental das misturas

\begin{tabular}{lccc}
\hline Mistura & \multicolumn{3}{c}{ Componentes } \\
\hline Gordura do leite & $\mathrm{x}_{1}$ & $\mathrm{x}_{2}$ & $\mathrm{x}_{3}$ \\
\cline { 2 - 4 } Óleo de girassol & 0 & 0 & 0 \\
Ésteres de fitosteróis & 0 & 1 & 0 \\
1 & 0,750 & 0 & 1 \\
2 & 0,675 & 0,075 & 0,250 \\
3 & 0,600 & 0,150 & 0,250 \\
4 & 0,525 & 0,225 & 0,250 \\
5 & 0,450 & 0,300 & 0,250 \\
\hline$x_{1}=$ gordura do leite; $\mathrm{x}_{2}=$ óleo de girassol; $\mathrm{x}_{3}=$ ésteres de fito- \\
steróis
\end{tabular}

\section{Interesterificação química}

Foram interesterificadas amostras de $350 \mathrm{~g}$ de cada componente isoladamente e de cada mistura, previamente secas em balão de vidro, sob pressão reduzida, acoplado a um rotaevaporador em banho de água a $95^{\circ} \mathrm{C}$. A cada porção foi misturado $0,5 \%(\mathrm{~m} / \mathrm{m})$ de catalisador metóxido de sódio em pó (Merck, Alemanha). A reação de interesterificação foi realizada sob agitação constante e pressão reduzida a $65-70{ }^{\circ} \mathrm{C}$ em balão de três bocas imerso em banho de água a $70{ }^{\circ} \mathrm{C}$, por $1 \mathrm{~h}$. Para interromper a reação foi adicionada água destilada. Para minimizar o escurecimento decorrente da reação e para absorver a umidade foram adicionados sílica em pó (Merck, Alemanha) e sulfato de sódio anidro (Labsynth, Brasil), respectivamente. Os reagentes foram filtrados a quente utilizando-se papel de filtro. ${ }^{17}$

\section{Composição em ácidos graxos}

Os ésteres metílicos de ácidos graxos para a análise foram obtidos segundo método descrito por Hartman e Lago. ${ }^{18}$ A composição em ácidos graxos foi determinada por cromatografia gasosa, segundo normas da AOCS, ${ }^{19}$ método Ce 1-62, em cromatógrafo a gás Varian GC 3400 CX (Varian, EUA) equipado com detetor de ionização de chama. Foi utilizada coluna capilar de sílica fundida CP WAX 52CB (Chrompack, EUA), com $30 \mathrm{~m}$ de comprimento x 0,25 mm de diâmetro interno e contendo $0,25 \mu \mathrm{m}$ de espessura de polietilenoglicol dentro da coluna. As condições foram: injeção split razão 50:1; temperatura da coluna: $75^{\circ} \mathrm{C}$ por $3 \mathrm{~min}$, programada até 150
${ }^{\circ} \mathrm{C}$ a $37,5^{\circ} \mathrm{C} / \mathrm{min}$ e novamente programada até $215^{\circ} \mathrm{C}$ a $3{ }^{\circ} \mathrm{C} / \mathrm{min}$; gás de arraste hélio, vazão $1,5 \mathrm{~mL} / \mathrm{min}$; gás make-up hélio, vazão 30 $\mathrm{mL} / \mathrm{min}$; temperatura do injetor $250^{\circ} \mathrm{C}$; temperatura do detector: 280 ${ }^{\circ} \mathrm{C}$. A composição foi determinada por comparação dos tempos de retenção dos picos com os dos respectivos padrões de ácidos graxos e por normalização de área, sendo expressa como porcentagem em massa. As amostras foram analisadas em duplicata e os resultados apresentados correspondem ao cálculo da média e desvio padrão.

\section{Ponto de amolecimento}

Foi determinado em triplicata pelo método oficial Cc 3-25 da AOCS,${ }^{19}$ utilizando tubo capilar aberto.

\section{Consistência}

A consistência das amostras foi determinada utilizando o analisador de textura TA-XT2 (Stable Micro Systems, Inglaterra), controlado pelo programa Texture Expert versão 1.22 (Stable Micro Systems, Inglaterra). As misturas foram aquecidas em forno de microondas, até a temperatura de $60-70{ }^{\circ} \mathrm{C}$, para a fusão completa dos cristais, e acondicionadas em béqueres de $100 \mathrm{~mL}$. O condicionamento foi efetuado por $24 \mathrm{~h}$ em geladeira comum $\left(5-8{ }^{\circ} \mathrm{C}\right)$ para a recristalização da gordura e posteriormente por $24 \mathrm{~h}$ em estufa a temperatura controlada entre 5 e $20^{\circ} \mathrm{C}$. Foi utilizado cone de acrílico com ponta não truncada e ângulo de $45^{\circ}$ para penetração de $10 \mathrm{~mm}$ a partir da superfície da amostra, com velocidade de $2 \mathrm{~mm} / \mathrm{s} .{ }^{20}$ Para o cálculo da consistência, foi utilizada a Equação 1, proposta por Haighton: ${ }^{21}$

$$
C=K \frac{W}{p^{1,6}}
$$

onde: $\mathrm{C}=$ consistência $\left(\mathrm{gf} / \mathrm{cm}^{2}\right) ; \mathrm{K}=$ fator dependente do ângulo do cone; $\mathrm{W}=$ força em compressão $(\mathrm{gf})$, para tempo de $5 \mathrm{~s} ; \mathrm{p}=$ profundidade de penetração $(\mathrm{mm} / 10)$.

As amostras foram analisadas em triplicata e os resultados correspondem à média e ao desvio padrão calculados.

\section{RESULTADOS E DISCUSSÃO}

A Tabela 2 apresenta a composição em ácidos graxos dos componentes puros. A gordura do leite apresentou grande variedade de ácidos graxos, com o número de átomos de carbono das cadeias variando desde ácidos graxos de cadeia curta até os de cadeia longa. Esta é uma propriedade característica da gordura do leite. ${ }^{22}$ A composição em ácidos graxos obtida experimentalmente difere ligeiramente da literatura consultada, principalmente em relação aos ácidos butírico (4:0) e capróico (6:0).

O ácido butírico é um ácido graxo presente exclusivamente na gordura do leite e comumente utilizado para quantificar a presença desta em alimentos. ${ }^{23}$ De acordo com a literatura, ${ }^{23-27}$ esse ácido graxo corresponde a cerca de 3-4\% do total de ácidos graxos da gordura do leite, porém, segundo os resultados obtidos experimentalmente, seu teor não passou de $0,1 \%$. É provável que uma parte desse ácido graxo tenha se perdido durante a preparação dos ésteres metílicos de ácidos graxos para a cromatografia gasosa, já que o ácido butírico é muito volátil, além de ser solúvel em água. O ácido capróico também apresenta elevada volatilidade e, da mesma maneira que o butírico, pode ter sido parcialmente perdido durante a preparação dos ésteres metílicos.

A gordura do leite é um dos lipídios naturais mais complexos em termos de composição em ácidos graxos e triacilgliceróis. É constituída de cerca de 15 ácidos graxos principais, porém mais de 
500 já foram caracterizados. ${ }^{27}$ Os resultados mostraram que os ácidos graxos saturados constituem a grande maioria, cerca de $67 \%$ do total. Os ácidos graxos predominantes foram palmítico, oléico, mirístico e esteárico, nesta ordem, sendo que sua soma corresponde a cerca de $82 \%$ do total. Os demais estiveram presentes em quantidades inferiores a $4 \%$ cada.

Tabela 2. Composição em ácidos graxos dos componentes puros

\begin{tabular}{|c|c|c|c|}
\hline \multirow[t]{2}{*}{ Ácido Graxo } & \multicolumn{3}{|c|}{ Teor \pm DP $(\%)$} \\
\hline & $\begin{array}{c}\text { Gordura } \\
\text { do leite }\end{array}$ & $\begin{array}{l}\text { Óleo de } \\
\text { girassol }\end{array}$ & $\begin{array}{l}\text { Ésteres de } \\
\text { fitosteróis }\end{array}$ \\
\hline $4: 0$ & $<0,1$ & $0,0 \pm 0,0$ & $0,0 \pm 0,0$ \\
\hline $6: 0$ & $0,3 \pm 0,0$ & $0,0 \pm 0,0$ & $0,0 \pm 0,0$ \\
\hline 8:0 & $0,8 \pm 0,0$ & $0,0 \pm 0,0$ & $0,0 \pm 0,0$ \\
\hline 10:0 & $2,4 \pm 0,0$ & $0,0 \pm 0,0$ & $0,0 \pm 0,0$ \\
\hline $12: 0$ & $3,2 \pm 0,0$ & $0,0 \pm 0,0$ & $0,0 \pm 0,0$ \\
\hline $14: 0$ & $12,2 \pm 0,1$ & $0,0 \pm 0,0$ & $0,9 \pm 0,1$ \\
\hline $14: 1$ & $1,3 \pm 0,0$ & $0,0 \pm 0,0$ & $0,0 \pm 0,0$ \\
\hline $15: 0$ & $1,4 \pm 0,0$ & $0,0 \pm 0,0$ & $0,0 \pm 0,0$ \\
\hline $16: 0$ & $33,6 \pm 0,1$ & $7,9 \pm 0,2$ & $6,2 \pm 0,1$ \\
\hline $16: 1$ & $1,9 \pm 0,0$ & $0,0 \pm 0,0$ & $0,0 \pm 0,0$ \\
\hline $17: 0$ & $0,6 \pm 0,0$ & $0,0 \pm 0,0$ & $0,0 \pm 0,0$ \\
\hline $18: 0$ & $12,1 \pm 0,0$ & $4,2 \pm 0,1$ & $2,3 \pm 0,0$ \\
\hline $18: 1$ & $23,7 \pm 0,1$ & $19,6 \pm 0,1$ & $32,5 \pm 0,9$ \\
\hline 18:1 trans & $3,2 \pm 0,0$ & $0,5 \pm 0,0$ & $1,6 \pm 0,1$ \\
\hline $18: 2$ & $1,6 \pm 0,0$ & $66,9 \pm 0,1$ & $17,1 \pm 1,1$ \\
\hline $18: 3$ & $0,3 \pm 0,1$ & $0,1 \pm 0,1$ & $3,4 \pm 0,1$ \\
\hline 18:2 (CLA) & $1,2 \pm 0,0$ & $0,0 \pm 0,0$ & $0,0 \pm 0,0$ \\
\hline $20: 0$ & $0,2 \pm 0,0$ & $0,3 \pm 0,0$ & $4,7 \pm 0,5$ \\
\hline $22: 0$ & $0,0 \pm 0,0$ & $0,5 \pm 0,0$ & $0,0 \pm 0,0$ \\
\hline $22: 1$ & $0,0 \pm 0,0$ & $0,0 \pm 0,0$ & $31,3 \pm 1,2$ \\
\hline Total & 100,0 & 100,0 & 100,0 \\
\hline Saturados & $66,8 \pm 0,0$ & $12,9 \pm 0,1$ & $14,1 \pm 0,5$ \\
\hline Monoinsaturados & $30,1 \pm 0,1$ & $20,1 \pm 0,1$ & $65,4 \pm 0,4$ \\
\hline Poliinsaturados & $3,1 \pm 0,1$ & $67,0 \pm 0,1$ & $20,5 \pm 1,0$ \\
\hline Total & 100,0 & 100,0 & 100,0 \\
\hline
\end{tabular}

O ácido linoléico conjugado (18:2 CLA) consiste em um grupo de ácidos graxos encontrado predominantemente no leite e na carne de animais ruminantes. $\mathrm{O}$ teor de CLA na gordura do leite geralmente se encontra entre 0,3 e 1,0\%, dependendo da estação do ano, alimentação do animal e processamento do alimento. ${ }^{28}$ O CLA tem sido intensamente pesquisado por suas propriedades anticarcinogênicas, proteção contra aterosclerose, caquexia e tratamento de diabetes. ${ }^{29}$ Neste experimento, foi possível detectar a presença de CLA nas amostras de gordura do leite no teor de $1,2 \%$ e nas misturas que a continham, na faixa de 0,6 a $1,1 \%$.

A composição do óleo de girassol está em conformidade com a legislação brasileira. ${ }^{30} \mathrm{O}$ ácido linoléico (18:2), presente em cerca de $67 \%$ da composição do óleo, caracteriza-o como um óleo do grupo deste ácido graxo.

Os ácidos oléico, linoléico e erúcico somados correspondem a mais de $80 \%$ dos ácidos graxos encontrados nos ésteres de fitosteróis. Devido à presença de mais de $30 \%$ do ácido erúcico (22:1), é provável que os fitosteróis tenham sido esterificados a ácidos graxos livres de óleo de colza. De acordo com a literatura, ${ }^{31} \mathrm{o}$ óleo de colza contém cerca de $40 \%$ de ácido erúcico e é produzido em larga escala na China (país onde se localiza o fabricante deste produto), além de Índia, Europa e Canadá. ${ }^{32}$

A Tabela 3 apresenta a composição em ácidos graxos das misturas. A adição de óleo de girassol à gordura do leite provocou diminuição no teor de ácidos graxos saturados. A mistura 3, que contém $15 \%$ de óleo de girassol, apresentou 53,0\% de ácidos graxos saturados e a mistura 5, que contém $30 \%$ de óleo de girassol, apresentou $42,7 \%$, contra $67,7 \%$ da gordura do leite pura. Dessa maneira, o grau de saturação da gordura do leite em um spread pode ser diminuído pela adição de um óleo vegetal, o que contribuiria não só para melhorar as características físicas do produto, como também suas propriedades nutricionais, além de diminuir os custos de produção. ${ }^{8}$

De modo geral, a adição tanto de óleo de girassol como dos ésteres de fitosteróis contribuiu para o aumento do grau de insaturação das misturas, já que os fitosteróis apresentaram apenas 14,1\% de ácidos graxos saturados.

A Tabela 4 apresenta a média e o desvio padrão do ponto de amolecimento das misturas, antes e após a interesterificação química.

A gordura do leite apresentou ponto de amolecimento de 33,1 ${ }^{\circ} \mathrm{C}$, valor semelhante ao encontrado por Rousseau e Marangoni, ${ }^{33}$ que determinaram o ponto de amolecimento da gordura do leite como sendo de $33,4{ }^{\circ} \mathrm{C}$. A mesma referência apresenta o ponto de amolecimento de uma mistura de proporção 80:20 (gordura do leite:óleo de canola), que era de $31,1^{\circ} \mathrm{C}$. Assim sendo, o ponto de amolecimento das misturas apresentou diminuição com o aumento na proporção de óleo de girassol.

De acordo com a literatura, ${ }^{25,34}$ o ponto de fusão do óleo de girassol está na faixa de -10 a $-12{ }^{\circ} \mathrm{C}$. O método utilizado, do tubo capilar aberto, não permite trabalhar nesta faixa de temperatura, já que é realizado em banho de água.

$\mathrm{Na}$ literatura não foram encontradas referências sobre o ponto de amolecimento de ésteres de fitosteróis. Experimentalmente, o valor encontrado foi de $24,3{ }^{\circ} \mathrm{C}$ e pôde-se observar sua contribuição para a diminuição do ponto de amolecimento da gordura do leite nas misturas que os contêm.

A interesterificação química provocou aumento no ponto de amolecimento da gordura do leite e das misturas. O óleo de girassol interesterificado também apresentou ponto de amolecimento abaixo de $0{ }^{\circ} \mathrm{C}$, não podendo dessa forma ser determinado pelo método do tubo capilar.

O aumento no ponto de amolecimento de misturas contendo gordura do leite interesterificadas quimicamente também foi observado por Rousseau e Marangoni. ${ }^{33}$ Segundo estes autores, existe uma relação diretamente proporcional entre o teor de triacilgliceróis trissaturados e o ponto de amolecimento. Esta relação também foi estabelecida por Rodrigues e Gioielli. ${ }^{35}$ A interesterificação química distribui aleatoriamente os ácidos graxos saturados presentes em grande quantidade na gordura do leite, formando mais triacilgliceróis trissaturados do que existiam com a tendência natural de distribuição. Na natureza, os ácidos graxos saturados da gordura do leite tendem a estar esterificados na posição $s n-2$, enquanto que os insaturados tendem a ficar nas posições $s n-1$ e $s n-3$.

Os ésteres de fitosteróis apresentaram aumento no ponto de amolecimento de 24,3 para $28,9^{\circ} \mathrm{C}$ após a interesterificação química. Segundo Piironen et al. ${ }^{36} \mathrm{e} \mathrm{Vu}$ et al.,${ }^{37}$ os fitosteróis são sólidos, o que dificulta sua solubilização em óleos e gorduras. Como exemplos, são citados os pontos de fusão do sitosterol, campesterol e estigmasterol como sendo $140,157-158$ e $170{ }^{\circ} \mathrm{C}$, respectivamente. Por essa razão, eles são esterificados com ácidos graxos, o que diminui seu ponto de fusão para faixas de temperaturas de processo normalmente utilizadas na indústria e aumenta sua solubilidade em óleos e gorduras. Com a interesterificação química realizada neste trabalho, os esteróis são separados dos ácidos graxos através do rompimento da ligação éster 
Tabela 3. Composição em ácidos graxos das misturas

\begin{tabular}{|c|c|c|c|c|c|}
\hline Ácido Graxo & & & Teor \pm DP $(\%)$ & & \\
\hline & $\begin{array}{c}\text { Mistura } 1 \\
(75,0: 0: 25,0) \\
\end{array}$ & $\begin{array}{c}\text { Mistura } 2 \\
(67,5: 7,5: 25,0) \\
\end{array}$ & $\begin{array}{c}\text { Mistura 3 } \\
(60,0: 15,0: 25,0) \\
\end{array}$ & $\begin{array}{c}\text { Mistura } 4 \\
(52,5: 22,5: 25,0) \\
\end{array}$ & $\begin{array}{c}\text { Mistura } 5 \\
(45,0: 30,0: 25,0) \\
\end{array}$ \\
\hline $4: 0$ & $0,1 \pm 0,0$ & $<0,1$ & $<0,1$ & $<0,1$ & $0,1 \pm 0,0$ \\
\hline $6: 0$ & $1,3 \pm 0,3$ & $0,4 \pm 0,0$ & $0,6 \pm 0,0$ & $0,3 \pm 0,0$ & $0,5 \pm 0,0$ \\
\hline $8: 0$ & $1,1 \pm 0,3$ & $0,6 \pm 0,0$ & $0,7 \pm 0,0$ & $0,6 \pm 0,1$ & $0,6 \pm 0,0$ \\
\hline 10:0 & $2,3 \pm 0,4$ & $1,7 \pm 0,0$ & $1,7 \pm 0,1$ & $1,5 \pm 0,1$ & $1,5 \pm 0,1$ \\
\hline $12: 0$ & $3,0 \pm 0,3$ & $2,4 \pm 0,0$ & $2,4 \pm 0,1$ & $2,0 \pm 0,1$ & $1,9 \pm 0,1$ \\
\hline $14: 0$ & $11,5 \pm 0,4$ & $10,2 \pm 0,1$ & $9,1 \pm 0,2$ & $7,9 \pm 0,3$ & $6,9 \pm 0,3$ \\
\hline $14: 1$ & $1,2 \pm 0,1$ & $1,1 \pm 0,0$ & $1,0 \pm 0,0$ & $0,9 \pm 0,0$ & $0,7 \pm 0,0$ \\
\hline $15: 0$ & $1,3 \pm 0,0$ & $1,3 \pm 0,0$ & $1,1 \pm 0,0$ & $0,9 \pm 0,0$ & $0,8 \pm 0,0$ \\
\hline $16: 0$ & $32,0 \pm 0,3$ & $30,0 \pm 0,1$ & $26,7 \pm 0,1$ & $24,0 \pm 0,2$ & $21,5 \pm 0,2$ \\
\hline $16: 1$ & $1,8 \pm 0,0$ & $1,7 \pm 0,0$ & $1,5 \pm 0,0$ & $1,3 \pm 0,0$ & $1,1 \pm 0,0$ \\
\hline $17: 0$ & $0,6 \pm 0,0$ & $0,6 \pm 0,0$ & $0,5 \pm 0,0$ & $0,4 \pm 0,0$ & $0,4 \pm 0,0$ \\
\hline 18:0 & $11,6 \pm 0,4$ & $11,1 \pm 0,0$ & $10,0 \pm 0,1$ & $9,1 \pm 0,2$ & $8,3 \pm 0,1$ \\
\hline $18: 1$ & $24,3 \pm 0,8$ & $24,3 \pm 0,1$ & $23,6 \pm 0,1$ & $23,3 \pm 0,5$ & $22,5 \pm 0,3$ \\
\hline 18:1 trans & $3,1 \pm 0,1$ & $2,9 \pm 0,0$ & $2,6 \pm 0,0$ & $2,6 \pm 0,2$ & $2,3 \pm 0,1$ \\
\hline $18: 2(n-6)$ & $2,4 \pm 0,0$ & $9,5 \pm 0,0$ & $16,4 \pm 0,2$ & $23,1 \pm 0,0$ & $29,1 \pm 0,3$ \\
\hline $18: 3$ & $0,5 \pm 0,0$ & $0,5 \pm 0,0$ & $0,5 \pm 0,0$ & $0,5 \pm 0,0$ & $0,5 \pm 0,0$ \\
\hline 18:2 (CLA) & $1,1 \pm 0,0$ & $1,0 \pm 0,0$ & $0,9 \pm 0,0$ & $0,8 \pm 0,0$ & $0,6 \pm 0,0$ \\
\hline 20:0 & $0,2 \pm 0,0$ & $0,2 \pm 0,0$ & $0,2 \pm 0,0$ & $0,2 \pm 0,0$ & $0,2 \pm 0,0$ \\
\hline $22: 1$ & $0,6 \pm 0,0$ & $0,5 \pm 0,0$ & $0,5 \pm 0,0$ & $0,6 \pm 0,0$ & $0,5 \pm 0,0$ \\
\hline Total & 100,0 & 100,0 & 100,0 & 100,0 & 100,0 \\
\hline Saturados & $65,0 \pm 0,0$ & $58,5 \pm 0,1$ & $53,0 \pm 0,4$ & $46,9 \pm 0,7$ & $42,7 \pm 0,7$ \\
\hline Monoinsaturados & $31,0 \pm 0,0$ & $30,5 \pm 0,1$ & $29,2 \pm 0,2$ & $28,7 \pm 0,7$ & $27,1 \pm 0,4$ \\
\hline Poliinsaturados & $4,0 \pm 0,0$ & $11,0 \pm 0,0$ & $17,8 \pm 0,2$ & $24,4 \pm 0,1$ & $30,2 \pm 0,3$ \\
\hline Total & 100,0 & 100,0 & 100,0 & 100,0 & 100,0 \\
\hline
\end{tabular}

Proporções das misturas: (gordura do leite:óleo de girassol:ésteres de fitosteróis)

Tabela 4. Ponto de amolecimento das misturas antes e após a interesterificação química

\begin{tabular}{lcc}
\hline Mistura & \multicolumn{2}{c}{ Ponto de amolecimento \pm DP $\left({ }^{\circ} \mathrm{C}\right)$} \\
\hline & Antes & Após IQ \\
\cline { 2 - 3 } Gordura do leite & $33,1 \pm 0,2$ & $37,1 \pm 0,2$ \\
Óleo de girassol & -10 a -12 (Literatura) & --- \\
Ésteres de fitosteróis & $24,3 \pm 0,0$ & $28,9 \pm 0,0$ \\
$1(75,0: 0: 25,0)$ & $31,1 \pm 0,1$ & $34,2 \pm 0,1$ \\
$2(67,5: 7,5: 25,0)$ & $27,7 \pm 0,9$ & $34,3 \pm 0,3$ \\
$3(60,0: 15,0: 25,0)$ & $27,5 \pm 0,4$ & $31,8 \pm 0,2$ \\
$4(52,5: 22,5: 25,0)$ & $29,1 \pm 0,0$ & $29,8 \pm 0,2$ \\
$5(45,0: 30,0: 25,0)$ & $26,0 \pm 0,2$ & $29,3 \pm 0,7$ \\
\hline
\end{tabular}

Proporções das misturas: (gordura do leite:óleo de girassol:ésteres de fitosteróis); IQ = Interesterificação química

que os une e se ligam a outros ácidos graxos, promovendo redistribuição entre esteróis e ácidos graxos, caracterizando a reação. Alguns esteróis podem não ter voltado a se ligar com ácidos graxos após sua separação durante a interesterificação química, permanecendo livres na mistura e contribuindo assim para o aumento no ponto de amolecimento dos ésteres de fitosteróis.

A Figura 1 apresenta a consistência em função da temperatura da gordura do leite e das misturas antes e após a interesterificação química. A gordura do leite pura apresentou consistência que variou de $12648 \mathrm{gf} / \mathrm{cm}^{2}$ a $5{ }^{\circ} \mathrm{C}$ até $922 \mathrm{gf} / \mathrm{cm}^{2}$ a $20{ }^{\circ} \mathrm{C}$ antes da intereste- rificação química, apresentando diminuição em função do aumento de temperatura. $\mathrm{O}$ mesmo ocorreu com as misturas, tanto antes como após a reação. Esse fenômeno pode ser explicado pela fusão gradual dos cristais em decorrência do aumento de temperatura e a conseqüente destruição da rede cristalina, o que confere plasticidade à gordura. ${ }^{38}$

A adição de óleo de girassol e ésteres de fitosteróis à gordura do leite provocou diminuição de sua consistência. O óleo de girassol é líquido nas temperaturas analisadas, o que causou a diluição da rede cristalina da gordura do leite. A adição de $15 \%$ de óleo de girassol e $25 \%$ de ésteres de fitosteróis (mistura 3) provocou diminuição da consistência da gordura do leite de 12648 para $1791 \mathrm{gf} / \mathrm{cm}^{2}$ a $5{ }^{\circ} \mathrm{C}$, o que corresponde a uma queda de $86 \%$ na consistência da gordura do leite. Essa diminuição é devida a uma rede cristalina estruturalmente mais frágil com a adição de apenas $35 \%$ dos outros componentes. ${ }^{13}$

A consistência dos ésteres de fitosteróis apenas pôde ser determinada a $5{ }^{\circ} \mathrm{C}$, apresentando o valor de $405 \mathrm{gf} / \mathrm{cm}^{2}$. Nas outras temperaturas em que foi analisado, o produto parecia apresentar alto grau de cristalização devido à sua cor opaca, porém supõe-se que os cristais não formavam uma rede cristalina estruturalmente semelhante às encontradas nas gorduras plásticas..$^{39,40}$ Esta estrutura cristalina é frágil em função das diferenças estruturais entre os esteróis e os ácidos graxos. Dessa maneira, o produto não apresentou estrutura suficiente para permitir a análise de consistência; apenas uma alta viscosidade pôde ser visualmente observada.

A consistência em geral diminuiu após a interesterificação química quando analisada a 5 e $10{ }^{\circ} \mathrm{C}$. A partir de $20^{\circ} \mathrm{C}$ até a fusão 

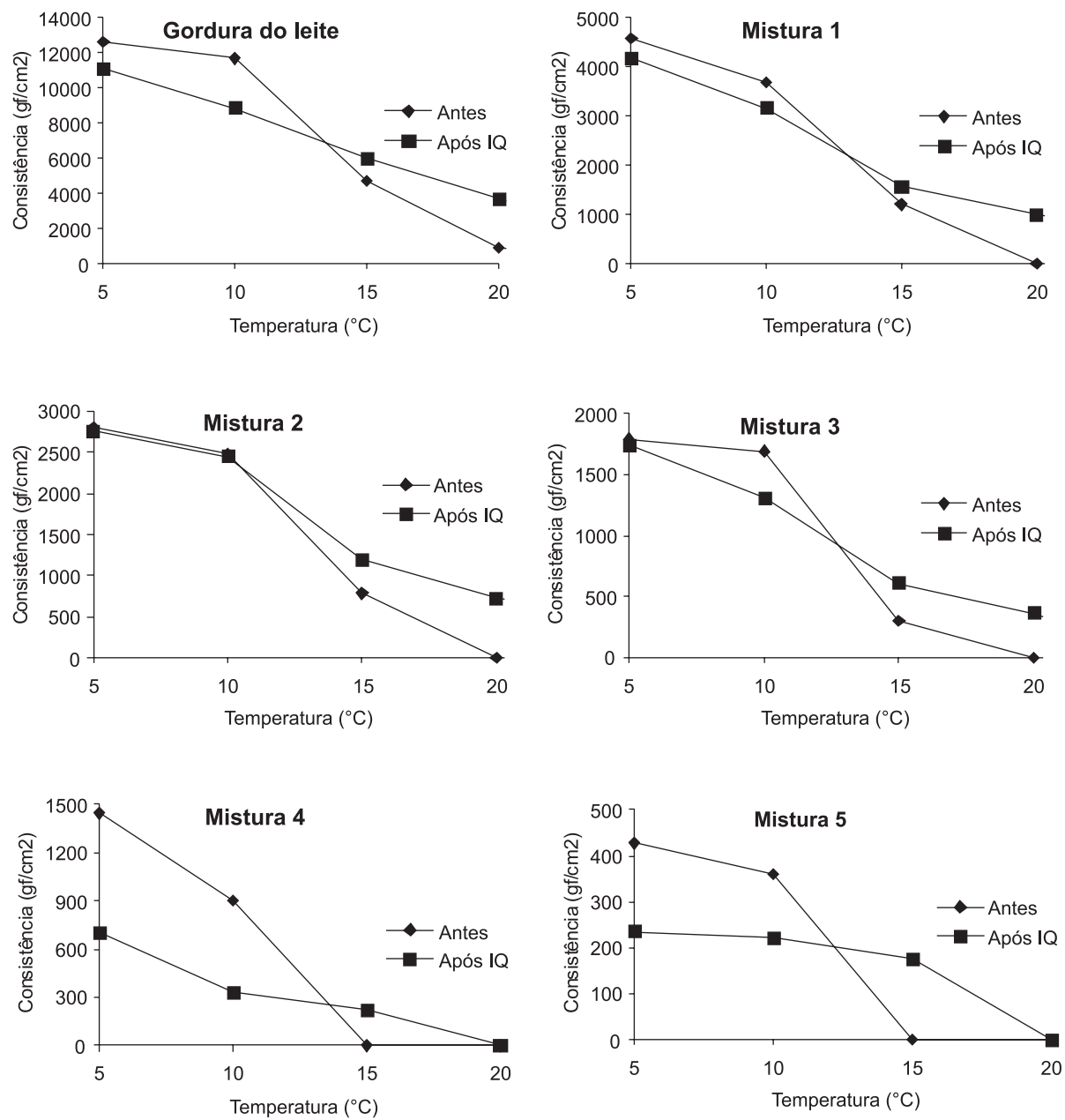

Figura 1. Curvas de consistência da gordura do leite e das misturas antes e após a interesterificação química

completa, a interesterificação química provocou aumento da consistência para todas as misturas. Esta diferença de comportamento das misturas interesterificadas em função da temperatura pode ser explicada pela incorporação dos ácidos graxos insaturados do óleo de girassol e dos ésteres de fitosteróis pelos triacilgliceróis da gordura do leite, diminuindo a inclinação das curvas de consistência das misturas em função da temperatura ${ }^{13}$

A Figura 2 apresenta a consistência das misturas a $20{ }^{\circ} \mathrm{C}$ antes e após interesterificação química em função da proporção de óleo de girassol. A mistura e a interesterificação química alteraram o comportamento reológico da gordura do leite por diferentes mecanismos. A simples mistura resultou apenas em diluição da rede cristalina da gordura do leite. Rousseau et al. ${ }^{13}$ realizaram mistura e interesterificação química entre gordura do leite e óleo de canola e determinaram o índice de dureza das misturas por penetração de cone a $5{ }^{\circ} \mathrm{C}$. Segundo os autores, a incorporação de $10 \%$ de óleo de canola não diminuiu substancialmente o índice de dureza da gordura do leite a $5{ }^{\circ} \mathrm{C}$, indicando que a gordura do leite foi capaz de acomodar maior proporção de óleo sem, no entanto, perder sua integridade estrutural. A adição de $20 \%$ de óleo de canola resultou em maior queda do índice de dureza, o que foi interpretado como sendo consequiência do enfraquecimento da estrutura cristalina. Para as misturas interesterificadas, o efeito de diluição das misturas foi intensificado pela incorporação dos ácidos graxos insaturados do óleo de canola pelos triacilgliceróis da gordura do leite, resultando em menor índice de dureza.

No presente trabalho, foi observado efeito semelhante, porém em diferentes proporções de gordura do leite e óleo de girassol. A gordura do leite interesterificada apresentou diminuição da consistência a $5^{\circ} \mathrm{C}$ de 11152 para $2752 \mathrm{gf} / \mathrm{cm}^{2}$ com a adição de 7,5\% de óleo de girassol e $25 \%$ de ésteres de fitosteróis e para $1748 \mathrm{gf} / \mathrm{cm}^{2} \mathrm{com}$ a adição de $15 \%$ de óleo de girassol e $25 \%$ de ésteres de fitosteróis, evidenciando a capacidade da gordura do leite de acomodar diferentes quantidades de óleo sem modificar sua integridade estrutural, dependendo da quantidade dos outros componentes. ${ }^{41}$ Mesmo havendo queda tão acentuada na consistência, estas misturas interesterificadas ainda apresentaram baixa plasticidade.

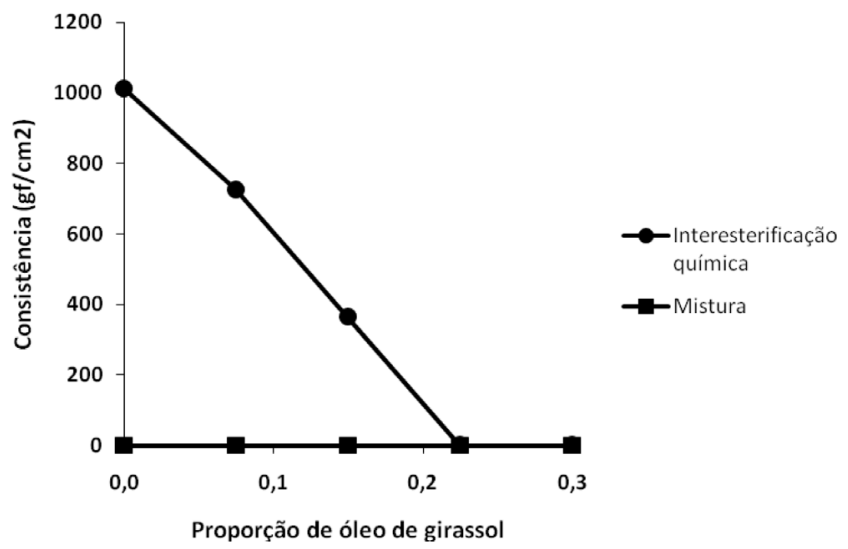

Figura 2. Consistência das misturas a $20^{\circ} \mathrm{C}$ antes e após a interesterificação química em função da proporção de óleo de girassol 


\section{CONCLUSÕES}

A partir dos resultados obtidos, conclui-se que o grau de saturação da gordura do leite em um spread pôde ser diminuído pela adição de óleos vegetais e ésteres de fitosteróis. Consequientemente, a gordura do leite apresentou menores pontos de amolecimento e consistência quando adicionada desses componentes. Ao contrário, a interesterificação química provocou aumento no ponto de amolecimento da gordura do leite e das misturas. A incorporação dos ácidos graxos insaturados do óleo de girassol e dos ésteres de fitosteróis pelos triacilgliceróis da gordura do leite como decorrência da reação química provocou diminuição da inclinação das curvas de consistência das misturas em função da temperatura, fazendo com que as misturas apresentassem diminuição da consistência a baixas temperaturas e aumento da consistência em temperaturas mais próximas à ambiente.

\section{AGRADECIMENTOS}

ÀFAPESP - Fundação de Amparo à Pesquisa do Estado de São Paulo, à CAPES - Coordenação de Aperfeiçoamento de Pessoal de Nível Superior, e ao CNPq - Conselho Nacional de Desenvolvimento Científico e Tecnológico, pelo apoio financeiro e bolsas concedidas.

\section{REFERÊNCIAS}

1. Semma, M.; J. Health Sci. 2002, 48, 7.

2. Lichtenstein, A. H.; Erkkila, A. T.; Lamarche, B.; Schwab, U. S.; Jalbert, S. M.; Ausman, L. M.; Atheroscl. 2003, 171, 97.

3. Gunstone, F. D.; Structured and Modified Lipids, Marcel Dekker: New York, 2001, p. 285-312.

4. Kaylegian, K. E.; J. Dairy Sci. 1999, 82, 1433.

5. Richards, N. S. P. S.; Gioielli, L. A.; Rev. Inst. Latic. Cândido Tostes 1999, 54, 204

6. Rodrigues, J. N.; Gioielli, L. A.; Anton, C.; Ciênc. Tecnol. Alim. 2003, $23,226$.

7. German, J. B.; Dillard, C. J.; Food Technol. 1998, 52, 33.

8. Rousseau, D.; Forestiere, K.; Hill, A. R.; Marangoni, A. G.; J. Am. Oil Chem. Soc. 1996, 73, 963.

9. Balcão, V. M.; Kempinem, A.; Malcata, F. X.; Kalo, P. J.; J. Am. Oil Chem. Soc. 1998, 75, 1347.

10. Marangoni, A. G.; Rousseau, D.; J. Am. Oil Chem. Soc. 1998a, 75, 1265.

11. Marangoni, A. G.; Rousseau, D.; J. Am. Oil Chem. Soc. 1998b, 75, 1633.

12. Rousseau, D.; Hill, A. R.; Marangoni, A. G.; J. Am. Oil Chem. Soc. 1996a, 73, 973 .

13. Rousseau, D.; Hill, A. R.; Marangoni, A. G.; J. Am. Oil Chem. Soc. 1996b, 73, 983 .
14. Ntanios, F.; Eur. J. Lipid Sci. Technol. 2001, 103, 102.

15. Weber, N.; Weitkamp, P.; Mukherjee, K. D.; Food Res. Int. 2002, 35, 177.

16. Nestel, P.; Cehun, M.; Pomeroy, S.; Abbey, M.; Weldon, G.; Eur. J. Clin. Nutr. 2001, 55, 1084.

17. Díaz Gamboa, O.W.; Gioielli, L.A.; Quim. Nova 2006, 29, 646.

18. Hartman, L.; Lago, R. C. A.; Lab. Pract. 1973, 22, 475.

19. AOCS; Official Methods and Recommended Practices of the AOCS, AOCS Press: Champaign, 1989; 1990; 1997; 1999.

20. D’Agostini, D.; Tese de Doutorado, Universidade de São Paulo, Brasil, 2001.

21. Haighton, A. J.; J. Am. Oil Chem. Soc. 1959, 36, 345.

22. Jensen, R. G.; Ferris, A. M.; Lammi-Keefe, C. J.; J. Dairy Sci. 1991, 74, 3228.

23. Molkentin, J.; Precht, D.; Eur. J. Lipid Sci. Technol. 2000, 102, 194.

24. Wright, A. J.; Hartel, R. W.; Narine, S. S.; Marangoni, A. G.; J. Am. Oil Chem. Soc. 2000, 77, 463.

25. O'Brien, R. D.; Fats and Oils: Formulating and Processing for Applications, Technomic: Lancaster, 1998, p. 14-15.

26. Hui, Y. H., ed.; Bailey's Industrial Oil and Fat Products, WileyInterscience: New York, 1996, vol. 2, p. 603-654; vol. 3, p. 1-63, p. 65-114.

27. Gunstone, F. D.; Harwood, J. L.; Padley, F. B.; The Lipid Handbook, Chapman and Hall: London, 1986.

28. Kühlsen, N.; Pfeuffer, M.; Soustre, Y.; MacGibbon, A.; LindmarkMansson, H.; Schrezenm, J.; Bul. Int. Dairy Fed. 2005, 393, 1.

29. Campbell, W.; Drake, M. A.; Larick, D. K.; J. Dairy Sci. 2003, 86, 43.

30. http://e-legis.bvs.br/leisref/public/showAct.php?id=18829\&word=, acessada em Janeiro 2006.

31. Stauffer, C. E.; Fats and Oils, Eagan Press: St. Paul, 1996, p. 131.

32. http://www.aphis.usda.gov/ppq/biotech/rapeseed.html, acessada em Maio 2003.

33. Rousseau, D.; Marangoni, A. G.; Food Res. Int. 1999, 31, 381.

34. Bockisch, M.; Fats and Oils Handbook, AOCS Press: Champaign, 1998, p. 296, 446-612.

35. Rodrigues, J. N.; Gioielli, L. A.; Food Res. Int. 2003, 36, 149.

36. Piironem, V.; Lindsay, D. G.; Miettinen, T. A.; Toivo, J.; Lampi, A. M.; J. Sci. Food Agr. 2000, 80, 939.

37. Vu, P. L.; Shin, J. A.; Lim, C. H.; Lee, K. T.; Food Res. Int. 2004, 37, 175.

38. Deman, J. M.; J. Am. Oil Chem. Soc. 1983, 60, 82.

39. Rodrigues, J. N.; Mancini-Filho, J.; Torres, R. P.; Gioielli, L. A.; Rev. Bras. Ciênc. Farm. 2004, 40, 505.

40. Rodrigues, J. N.; Torres, R. P.; Mancini-Filho, J.; Gioielli, L. A.; Food Res. Int. 2007, 40, 748.

41. De, B. K.; Hakimji, M.; Patel, A.; Sharma, D.; Desai, H.; Kumar, T.; Eur. J. Lipid Sci. Technol. 2007, 109, 32. 